\title{
What is literariness? Three components of literary reading
}

\author{
David S. Miall and Don Kuiken \\ Departments of English and Psychology, University of Alberta \\ Discourse Processes, 28 (1999), 121-138. \\ (C) Copyright Lawrence Erlbaum Associates
}

\begin{abstract}
It is now widely maintained that the concept of "literariness" has been critically examined and found deficient. Prominent postmodern literary theorists have argued that there are no special characteristics that distinguish literature from other texts. Similarly, cognitive psychology has often subsumed literary understanding within a general theory of discourse processing. However, a review of empirical studies of literary readers reveals traces of literariness that appear irreducible to either of these explanatory frameworks. Our analysis of readers' responses to several literary texts (short stories and poems) indicates processes beyond the explanatory reach of current situation models. Such findings suggest a threecomponent model of literariness involving foregrounded textual or narrative features, readers' defamiliarizing responses to them, and the consequent modification of personal meanings.
\end{abstract}

What sort of activity is the reading of literature? There are several possible answers to this question, depending upon the respondent's theoretical commitments. Reading literature may, for example, be understood as a type of discourse processing. That is, it may be a "second order effect," a particular organization of the cognitive processes that are also apparent in ordinary prose or conversation (Hobbs, 1990, p. 165). Or reading literature may be the outcome of rhetorical devices designed to promote a particular ideology. In this view, "Anything can be literature" or "can cease to be literature" depending upon the prevailing doctrine (Eagleton, 1983, p. 10). Theories of both kinds, whether grounded in cognitive psychology or in postmodern theory, do not accord literary texts their distinctiveness; both imply that any text, whether literary or not, depends on functions common to all texts. There purportedly are no processes unique to the act of literary reading (Miall \& Kuiken, 1998).

In this paper we will offer a challenge to these perspectives, focusing on our attempt to reconceptualize "literariness." Unlike Jakobson, who first coined this term in 1921 (Erlich, 1981), we suggest that literariness cannot be defined simply as a characteristic set of text properties. On the other hand, neither can it be regarded as the result of applying a set of conventions (cf. Zwaan, 1993, pp. 7-15). We will argue instead that literariness is the product of a distinctive mode of reading that is identifiable through three key components of response to literary texts. We will describe several studies that provide evidence favoring this conception of literariness, evidence that appears difficult to understand either within the discourse processing or postmodern theoretical framework. We begin with one reader's account of a moment during reading that shows 
evidence of all three components of literariness.

In a recent empirical study, we invited 30 readers of two Coleridge poems to comment on the passages in these poems that they found striking. We will focus on one participant's commentary (reported more fully by Sikora, Kuiken, \& Miall, 1998) on the opening lines from "The Nightingale": "No cloud, no relique of the sunken day / Distinguishes the West..." The reader is explaining why she finds this passage striking:

Because of the way that he says a 'sunken day' and there is 'no relique'; so there's nothing there. I like it because it's unusual to see the days sunken, instead of the sun. I think that's what gives it it's sense of desolation. I just picture this huge, huge expanse of sky with really nothing else on the horizon. There's also kind of a sense of timelessness; because relics are something that are old and sunken, it sounds like a sunken ship, something that's been there for hundreds of years and nobody knows about it, but it's something that's happening right now and it's kind of before dark but after day. It's just kind of a nothing time, well not a nothing time but a time that can't be described, that can't be categorized.

In these comments, we detect the three components of response that constitute literariness:

1. The reader initially comments on the style of the poem, "the way" it is written: "Because of the way that he says, a 'sunken day' and there is 'no relique'..." The first component of literariness, as this reference suggests, is the occurrence of stylistic variations that are distinctively (although not uniquely) associated with literary texts: in the present case, a metaphor ('sunken day') and an archaic, polysemous noun ('relique'). (Below, we will widen this component to include narrative features.)

2. The reader has been struck by these stylistic variations, remarking that "it's unusual to see the days sunken, instead of the sun." The more usual or familiar locution, the sunken sun, has been replaced by a phrase that unsettles the reader's conventional understanding of faded day. The second component of literariness is the occurrence of this type of defamiliarization.

3. The reader is prompted to reflect on the implications of this defamiliarizing phrase, implications that do not seem immediately obvious since several feelings and images are called to mind before a provisional judgment is reached. The phrase refers, she eventually concludes, to "a nothing time . . . a time that can't be described, that can't be categorized." In other words, the reader has been prompted to put in place a new sense of time, but her difficulty in finding the appropriate words attests to the reinterpretive effort required. Thus the third component of literariness is the modification or transformation of a conventional concept or feeling.

The reader commentary we have just cited is unusual in exhibiting within a short space all three components of the phenomenon we have termed literariness. But we suggest that all three must be present and must interact to constitute literariness. Briefly, literariness is constituted when stylistic or narrative variations strikingly defamiliarize 
conventionally understood referents and prompt reinterpretive transformations of a conventional concept or feeling. Each component of literariness (stylistic or narrative variations, defamiliarization, reinterpretive transformations) may occur separately: advertising copy, for example, often makes use of arresting stylistic features; traumatic events may precipitate the transformation of conventional concepts and feelings. But we suggest that the key to literariness is the interaction of these component processes. Rather than any special content, contextual conditions (e.g., educational practices), or ideological functions, literature is unique because it initiates a distinctive form of psychological change. This process of change is initiated under no other conditions that we are aware of, although comparable processes may be operative during response to some works of visual art, music, dance, or film.

The three components of literariness can be elaborated somewhat more technically in the following way. Literary texts contain features that stand out from ordinary uses of language-or are "foregrounded" (Mukarovský's term, 1964/1932). In the example we have cited, the poem deploys stylistic features within molecular noun phrases, but foregrounding may also be evident within molar narrative structures, through devices that provide shifts in point of view, deformations of the temporal framework, or insights into character perspective through free indirect discourse (these are just a few of the many devices that could be cited). Our proposal, in fact, is in accord with an extensive tradition of theorizing about literary stylistics from British Romantic writers such as Coleridge and Shelley, through the Russian Formalists, the Prague Linguistic Circle (of whom Mukarovský was a member), to more recent work by Leech, Fowler, Short, Widdowson, and others (reviewed by Van Peer, 1986). In narrative terms, also, we can refer to the influential work of Iser (1978): pointing to the existence of unexpected gaps or blanks in literary narrative, Iser showed how readers are driven to construct their own network of meanings, working beyond the referential to an aesthetic encoding of the text (cf. Iser, 1978, p. 92-3). Our approach entails specifying in detail, at the local textual level, what stylistic and narrative features prompt readers' reinterpretations (hence enabling a predictive model that can be subjected to empirical study). In general, the literary features we have mentioned are identifiable in relation to the norms of language or narrative that are apparent in ordinary discourse (e.g., the language and narrative forms used in newspaper articles), but they may also occur in relation to local norms created by a prevailing style or narrative strategy within the text itself. Hunt and Vipond's (1986) discourse evaluations, for example, are noticed because they stand out from local text norms.

In the literary context, readers find these variations striking and evocative. While such features may occur in ordinary prose, they tend to do so at random and to convey either no meaning or a meaning that is at odds with the situation model overtly developed in the text, thus readers are likely to ignore them. But for literary readers attention is captured and held, and, for a moment, familiar and conventionally understood referents seem less familiar, as though there is something "more" to them than can be immediately grasped (defamiliarization). In response, as readers reflect on the implications of a defamiliarizing expression, their reinterpretive effort modifies or transforms their conventional concepts or feelings. Such reinterpretation usually follows an interval during which readers search (not necessarily consciously) for an appropriate context within which to locate or generate such new understanding. Our empirical studies indicate that feeling is the primary vehicle for this search.

It is, of course, possible to read a text in a "literary" manner despite the absence of foregrounded stylistic or narrative features: that is, a "found poem" or a newspaper 
article might be presented to readers as literary. A well-known demonstration of this point is provide by Fish's (1980) anecdote of the "poem" on the blackboard: actually consisting of the names of five literary critics, his students were ready to interpret this as a poem when instructed to do so. Zwaan's studies (1993) have shown that when readers are led to believe that a text is literary (although some of his extracts were from newspaper articles), they read more slowly and recalled more of the surface details of the text than readers who encountered the same text within a newspaper-reading condition. While such reader behavior reflects the impeded reading rate that would be expected in response to a text containing foregrounding, we argue that this is a necessary but insufficient condition of literary reading. Without significant foregrounded passages to process, Zwaan's readers are unlikely to have had a recognizably literary experience, involving the modification or transformation of existing concepts or feelings. Although one cannot rule this out, such an occurrence would require a special conjunction of text and reader. Untypical cases such as Fish's anecdote or Zwaan's newspaper readers are suggestive but marginal, offering an insufficient basis on which to found a theory of literary reading.

Thus we suggest that literariness conceived as a transforming process is not merely conventional, the result of acculturation; nor is it the result of a "control" process, put in place by previous experience with literary genres, although knowledge of such genres may facilitate processing once a text is recognized as literary. Rather, literariness at its most fundamental level is an outcome of our psychobiological inheritance that involves linguistic capabilities, feeling expression, and self-perception. Drawing on these capacities, literary response plays a critical role in alerting us to alternative perspectives on our selves and on our social and natural environments. Several aspects of this view challenge contemporary conceptions of literary response. In what follows, we look critically at two representative examples of such contemporary frameworks, and confront them with some empirical evidence for the distinctiveness of literary reading. Our first example is taken from the arguments of a postmodern critic, Barbara Herrnstein Smith in Contingencies of Value (1988).

\section{The Stability of Literariness}

Like other contemporary critics, such as Fish (1980, 1989) and Eagleton (1983), Smith (1988) is most concerned about the meaning and value of literary texts. How does literature come to have the value it does, inspiring us to give it the careful interpretive attention that we do? According to Smith, literary value is determined extrinsically, as a product of historical circumstances; what is deemed of value in one epoch may well be valued quite differently or not at all in another (cf. Eagleton, 1983, pp. 10-11). In this view, all aspects of evaluative judgments are dependent on the social position of the evaluator; nothing is dependent on the qualities of the work of art itself: "there are no functions performed by artworks that may be specified as generically unique" (Smith, 1988 , p. 35). To the extent that a reader identifies features or properties of a work for attention, these are "the variable products of the subject's engagement with his or her environment under a particular set of conditions" (pp. 31-2). Thus, we are asked to suppose that the reader we cited earlier singles out the metaphor in Coleridge's line because she has been subjected to educational practices that promote such activities and valorize the states of mind that result.

Smith suggests that those in control of aesthetic judgement (usually in academia) expect texts to perform the functions they find proper or desirable, finding any other functions irrelevant or improper. This controlling group is also said to deem necessary the 
conditions under which its members engage literary texts, while other conditions are considered irregular or substandard (p. 41). However, this imputes much more power to the "controlling" group than it actually possesses; our own empirical studies of student readers, such as the reader we have cited, show far more divergent reading practices and varied understandings of literature than Smith's account would allow. In their interpretations and evaluations, actual readers go their own way, especially when unconstrained by classroom structures of authority.

Nonetheless, these readers' diverse construals of meaning are neither irresponsible nor whimsical, as is sometimes suggested (Smith, 1988, p. 11; Fish, 1989, p. 83). We have been able to demonstrate in several ways that the formal, stylistic features of literary texts persistently influence the reading process-even when readers' interpretations and valuations are highly variable. For example, we have coded the segments of a short story (usually one sentence) for the presence of stylistic features, i.e., foregrounding (Mukarovský, 1964/1932). When we ask readers to read the story, we invariably find a substantial correlation between the amount of foregrounding and the reading time for each segment, as well as significant correlations between foregrounding and readers' ratings of each segment for strikingness, feeling, and uncertainty. That is, readers spend more time reading segments high in foregrounding, and they find those segments more striking, evocative of more feeling, and productive of greater uncertainty (Miall and Kuiken, 1994a). Since these relationships are found whether the readers are students of literature or students with little or no current interest in reading literature, this is evidence that the response to foregrounding is independent of literary training (Van Peer, 1986; Steen, 1994).

The role of foregrounded features in transcending the readers' cultural background is also suggested by another study, based on Coleridge's long poem "The Rime of the Ancient Mariner" (Coleridge, 1924/1817). Here, taking the extensive critical literature on the poem from 1900 to 1991, we counted the occurrence of quotations from the poem's 625 lines in 166 articles and book chapters. Then, during the study from which we have already cited one reader's comments (Sikora, Kuiken, \& Miall, 1998), 30 readers nominated and commented on five passages that they found striking. The correspondence between the frequency with which lines were selected from the poem by the critics and by the student readers was assessed: this correlation was substantial and highly significant, $\mathrm{r}(623)=.44, \mathrm{p}<.0001$. Informally we observed that, for both groups, the most frequently selected lines of the poem were either high in foregrounding or captured moments of considerable narrative importance (with ambivalent or multivalent meanings). Passages from the poem apparently have the power to attract attention in ways that transcend time (1900-1991), literary experience (student or critic), or critical perspective (psychoanalytic, new historicist, etc.).

Smith (1988) argues, in contrast, that it is a mistake to attribute commonalities in response to "fundamental 'traits,' recurrent 'features,' or shared 'properties' of valued works. The attempt to locate invariance in the nature (or, latterly, the structure) of the works themselves is . . . no less misguided than the search for essential or objective value-and is, in fact, only another form of that search" (p. 15). Thus Smith (characteristically among postmodern theorists) regards the identification of features in a literary text that direct reader response to be a form of essentialism. In her account, the "properties" or "features" of a text are "at every point the variable products of particular subjects' interactions with it" (p. 48). There can be no fixed, determinate features, influencing all readers. These, when they appear, flow from the valuations enforced on readers by what Stanley Fish (1980) calls the interpretive community; they are a product 
of educational and cultural norms.

It is quite true, as Smith says, that "literary value is not the property of an object or a subject but, rather, the product of the dynamics of a system" (p. 15). But she goes on to claim: "As readers and critics of literature, we are within that system"; thus, because we "have particular interests, we will, at any given moment, be viewing it from some perspective" (p. 16). What is missing from this account, we suggest, is that these interests, in part, follow from literary reading rather than shaping it in advance. So, regardless of interpretive community, a reader will regularly notice distinctive stylistic and narrative features in a text and find them strikingly (i.e., interest-ingly) defamiliarizing. In this respect, the reader's conventional perspective does not direct the reading experience. On the contrary, it is precisely the conventional perspective of the reader that the literariness of the text calls into question. In our first example, for instance, the reader of Coleridge's "The Nightingale" brought to the reading situation her prior and conventional perspective on time-and found this perspective unsettled by the opening lines of the poem. If our interests were invariably in control, as Smith supposes, these strikingly defamiliarizing passages in literary texts would be inconceivable.

The strikingness of literature occurs against a background of familiarity and habituation. During literary reading, the perspectives that we have, perhaps unthinkingly, acquired from our culture are especially likely to be questioned. If so, this points to the adaptive value of literature in reshaping our perspectives and providing us with greater flexibility, especially by impelling us to reconsider our system of convictions and values. Although the processes embodied by foregrounding and defamiliarization have been central to literary theorists from the time of the Romantic theorists, such as Coleridge and Shelley, Cook (1994, p. 10) is one of the few contemporary theorists of discourse analysis to put forward, as we do (Miall, 1989), schema-refreshment as a characteristic component of literary response. Our proposal, as we show later, diverges from Cook's in accommodating the role of feeling, which we see as central to the reinterpretive processes evoked by literary texts.

\section{Beyond the Narrative Situation}

The difficulty of identifying and understanding what, if anything, is characteristic of the response to literature is also apparent in recent studies of discourse processing. In this section we will refer briefly to two important studies of narrative comprehension (Zwaan, Magliano, \& Graesser, 1995; Trabasso \& Magliano, 1996) and show their relation to the conception of literariness that we have proposed. Our aim is to suggest that, despite the technical sophistication of discourse processing theory (Graesser, Millis, \& Zwaan, 1997), literariness involves processes that appear beyond the power of this approach to explain (cf. Miall \& Kuiken, 1994b). These processes may include, but almost certainly go beyond, the particular "control processes" that Zwaan $(1993,1996)$ has proposed to account for the "inconsiderate" nature of literary texts.

Apart from Zwaan's (1993, 1996) proposal, which is situated within Kintsch's (1988) Construction-Integration model, the goal of discourse processing theory has been to articulate the processes by which readers comprehend all texts, whether expository or narrative. Van Dijk (1979), for example, saw no issues unique to literary comprehension and urged its absorption into a general theory of discourse processing. More recently, in their elaboration of the situation model perspective, authors such as Zwaan and Radvansky (1998) assume that understanding the situation model in a narrative text is 
"tantamount to the successful comprehension of a text" (p. 162). This, we will show, is by no means clear; current studies of how readers form situation models have failed to address the significant contributions of literariness to the reading process.

Zwaan and his colleagues (Zwaan, Magliano, \& Graesser, 1995; Zwaan, Langston, \& Graesser, 1995) have provided persuasive evidence of the reader's construction of the situation model during response to narrative. The situation model consists of arguments (or propositions) and their relationships (connections between referents) and the need to register shifts in time, space, and causation. When segments of a short story are coded for these components, the prediction of reading times using multiple regression techniques can be used to indicate processing requirements in constructing the situation model (Zwaan, Magliano, \& Graesser, 1995). A situation model, however, represents the array of cognitive processes necessary for understanding any narrative. It is this perspective that literary narratives, with their defamiliarizing power, seem particularly likely to challenge.

While certain stylistic variations, such as temporal deviations, may be captured by the situation model, the broader array of foregrounded features falls outside its scope. To examine this possibility, we reanalyzed responses to one of the stories studied by Zwaan et al. (1995), Elizabeth Bowen's (1981) "The Demon Lover." The segments of the story, as determined by Zwaan et al., were coded for foregrounding. For example, in the sentence "She stopped dead and stared at the hall table" we noted the occurrence of the repeated "st" sound, the pair of adjacent stresses on both "stopped dead" and "hall table" (which slows the rate of reading), and the metaphoric term "dead," which, while a conventional expression, begins to seem ominous in the context of the story. Our count of these features at the phonetic and semantic levels, converted to standard scores and summed, constituted the code for foregrounding for this sentence (many segments also show foregrounding at the grammatical level, which contributes to the overall score). We have found that a higher score predicts longer reading times (Miall \& Kuiken, 1994a).

The foregrounding code and those for the situation model were then compared as predictors of the reading times obtained by Zwaan et al. in a regression model (based on item analysis). In addition, we included a perspective code representing degree of proximity to the point of view and feelings of the main character (explained further below), the serial position of the sentences (since readers tend to speed up during their reading of a story), and the syllable count per segment (the last two variables are included in the analysis principally in order to partial them out, since they are of no theoretical interest). While the overall result (see Table 1) was, as expected, very significant, $F(9,139)=183.24, p<.0001$, of greater importance is evidence that the independent contribution of foregrounding to the prediction of reading time was comparable to that for the new arguments component of the situation model and greater than that for any of the other components of the situation model. It should also be noted that foregrounding and new arguments are independent influences on reading times: partial correlation (controlling for number of syllables), $r(147)=.059$, ns.

\section{TABLE 1}

Correlations between Individual Variables and Mean Reading Times following Multiple Regression Analysis of Story Factors for "The Demon Lover" 


\begin{tabular}{|c|c|c|}
\hline$d f=147$ & Simple & Partial \\
\hline Serment & & \\
\hline $\begin{array}{l}\text { Segment } \\
\text { Svllables }\end{array}$ & -.15 & $-0.21 * *$ \\
\hline $\begin{array}{l}\text { Syllables } \\
\text { New Arguments }\end{array}$ & $0.94 * * * *$ & $0.84 * * * *$ \\
\hline New Arguments & $0.72 * * * *$ & $0.30 * * * *$ \\
\hline Argument overlap & 0.11 & -0.07 \\
\hline Time & 0.14 & $0.16 *$ \\
\hline Space & 0.13 & 0.08 \\
\hline Cause & $0.24 * * *$ & 0.06 \\
\hline Perspective & $0.21 * *$ & -0.01 \\
\hline Foregrounding & $0.72 * * * *$ & $0.26 * * * *$ \\
\hline
\end{tabular}

What are the implications of these findings for our conception of how readers understand literary texts? How does the response to foregrounding relate to the pattern of inferences commonly analysed in discourse studies? These questions can be pursued further by examining think-aloud protocols gathered while people read a literary story. Our approach to this task may be compared to the strategy of Trabasso and Magliano (1996), who outlined a theoretical approach to analysing readers' verbal comments in response to a simple story (a very short narrative about Ivan the warrior who kills a marauding dragon). They showed that the inferences generated by their readers fell into one of three categories: backward looking (explanation), concurrent (associations), or forward looking (predictions). Explanation is backward oriented because it serves "to unite the focal sentence with either text information or prior knowledge-based inferences." Explanations are concerned with the reasons why something occurs; they refer to "external states, events, goals and other internal states, emotional reactions, actions, and outcomes that signal goal success or failure"; explanations, in other words, "provide the physical, motivational, and psychological causes, or enabling conditions" to understand a given episode (p. 259). Explanations are the most common type of comment in the protocols analysed in their study. The frequency of comments was: explanations, 50\%; associations, $16 \%$; predictions, $9 \%$; metacomments, $4 \%$; and paraphrases, $21 \%$.

In comparison, in a study of responses to a literary story, the think-aloud protocols that we analyzed (Kuiken \& Miall, 1995) contained a somewhat lower proportion of explanations-as well as a variety of other categories not envisaged by Trabasso and Magliano (1996). The story, "The Trout" by Seán O'Faoláin (1980-82), was divided into 84 segments (usually one sentence), which 30 participants read one at a time on a computer screen. As they read, they commented on their changing understanding of the story. The resulting think-aloud protocols were analysed into constituents, using methods in which recurrent expressions of similar meanings across protocols, rather than theory, determined the categories that were formed (Kuiken, Schopflocher, \& Wild, 1989). For the present analysis, the resulting constituents were grouped into 14 types: these are shown with example constituents in Table 2 . The frequency of constituents of each type was also compiled for each of the 84 story segments.

\section{TABLE 2}

Types of Comment in Analyses of Think-Aloud Protocols for "The Trout" with Example Comments 


\section{Character Explanation}

Julia will do it again for the excitement

Elaborative Explanation

The problem of the trout is still unresolved

Association

The tunnel is dark and cold

Anticipation

Julia will throw the trout in the river

World knowledge

The Dark Walk could be in Britain or Newfoundland

Quotations

"cool ooze of the river's bank"

Style

I notice the use of a simile in describing the fish

Imagery

I get an image of the scene of the trout

Query

I wonder if Julia is afraid or does not want to get caught

Surprise

I am struck that the trout is described as "panting"

Reader emotion

I am glad Julia is troubled

Thematizing

Again we have the symbolism of the trout in a prison

Literary reference

The character's dialect reminds me of Wuthering Heights

Reading awareness 
As shown in the left-hand section of Table 3 below, explanations of character actions were the most common type of constituent; if these are added to the more general elaborative explanations made by participants, explanations accounted for approximately $36 \%$ of the total comments. Although our principles for coding types of comments differed from those of Trabasso and Magliano (1996), the broad categories are sufficiently similar to compare our proportions with theirs. Besides the relatively few explanations, it should be noted that our story elicited fewer associative and anticipatory comments. Most noteworthy, however, is the large number of comments that are arguably distinctive to the process of literary reading:

1. Readers frequently appear to be struck by the surface code of the story, prompting them to repeat phrases verbatim while reading $(21.5 \%$ of comments);

2. They are alert to formal features of the text, commenting rather often on stylistic aspects of the story $(7.6 \%)$;

3. They often find the story puzzling or unclear, leading to a high proportion of queries about meaning $(10.1 \%)$;

4. They sometimes express surprise in response to story elements $(4.1 \%)$; and

5. They occasionally formulate interpretive ideas while reading, an activity we have termed thematizing (3.1\%).

\section{TABLE 3}

Frequency of Types of Commentary in Talk-Aloud Protocols for "The Trout" with Correlations by Segment with Story and Reader Variables

(controlling for syllables)

Reader Variables

\begin{tabular}{|c|c|c|c|c|}
\hline $\begin{array}{ll}\text { Protocol types } \\
\text { readtim } & \text { uncert }\end{array}$ & $\begin{array}{c}\text { Scored* Percent } \\
\text { import }\end{array}$ & foregr & newarg & persp \\
\hline $\begin{array}{ll}\text { Character explan. } \\
-.069 & -.099\end{array}$ & $861 \quad 33.6 \%$ & -.179 & -.171 & $.262 *$ \\
\hline $\begin{array}{l}\text { Elaborative expl. } \\
-.141\end{array}$ & ${ }^{53} .063^{2.1 \%}$ & .085 & .051 & -.069 \\
\hline $\begin{array}{l}\text { Association } \\
.402 * * *\end{array}$ & ${ }^{166}-.163$ 6.5\% & $.289 * *$ & .159 & - .230* \\
\hline $\begin{array}{l}\text { Anticipation } \\
-.007 \quad .033\end{array}$ & $84.145^{3.3 \%}$ & .068 & -.029 & .031 \\
\hline
\end{tabular}

Story Variables

Partial Correlations 


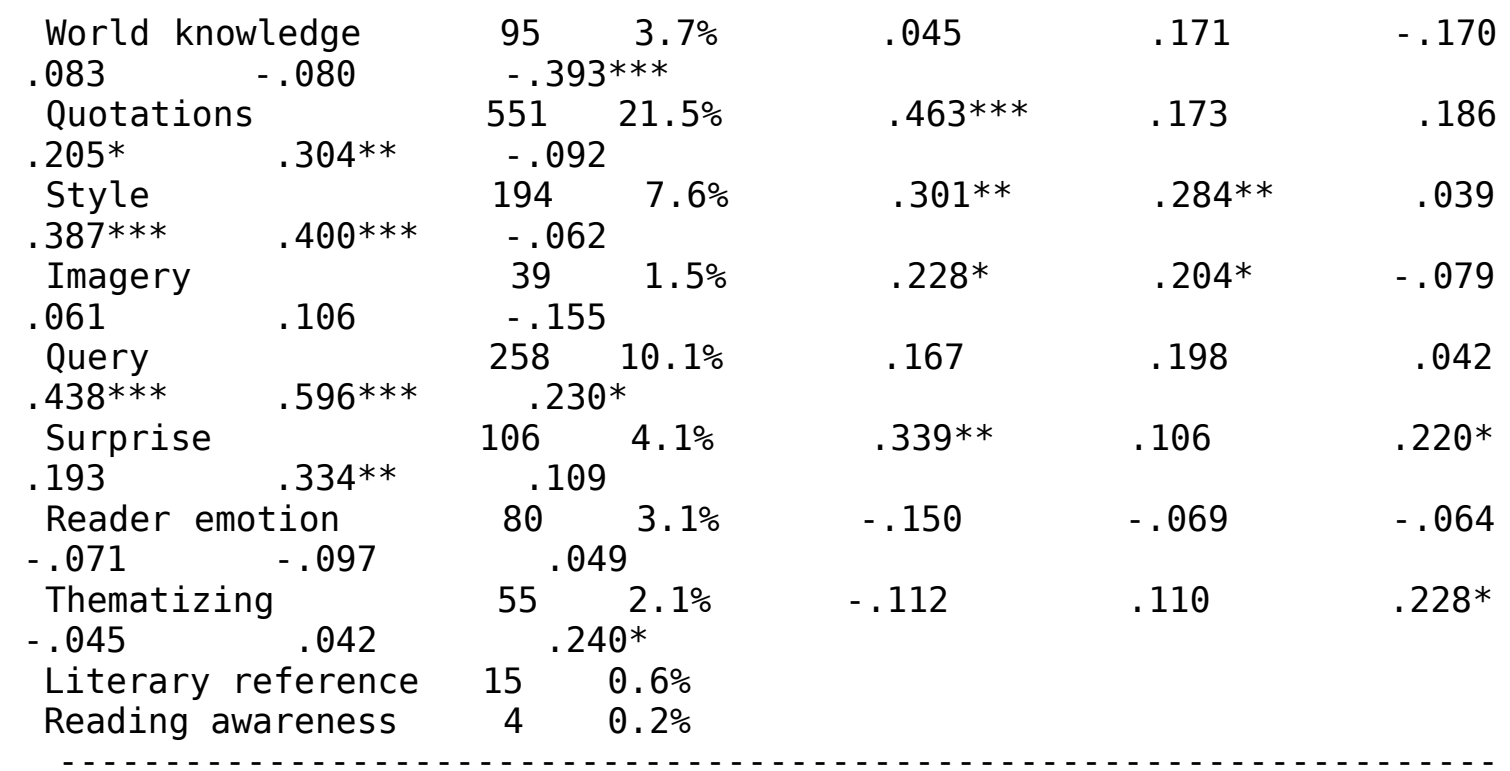

Intercorrel

ation of Story and Reader Variables

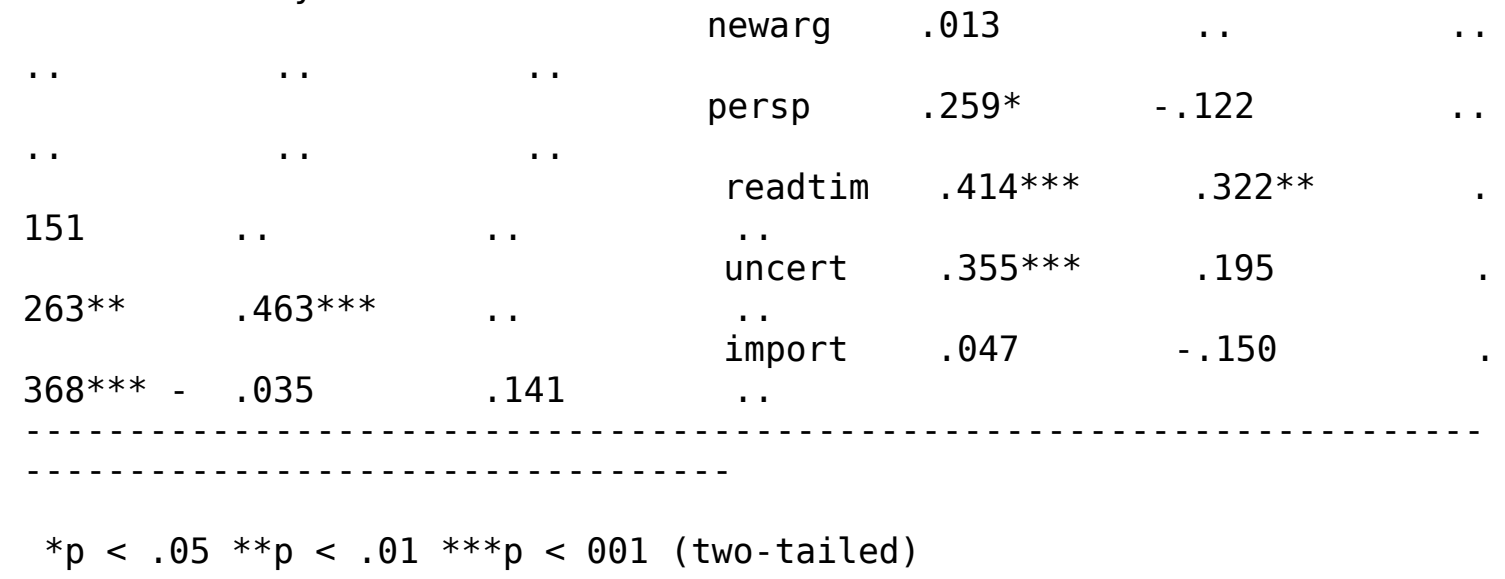

*2561 segment constituents out of 3183 were scored $(80.5 \%)$; the remaining constituents were based on sections of the story larger than the segment.

Literary readers thus undertake interpretive activities not generally accounted for in the discourse processing tradition, even when a literary narrative is under consideration (as in Zwaan, Magliano, \& Graesser, 1995). To determine the origins of such comments, the frequency (per segment) of each type of comment was correlated with other variables, following the "three-pronged" approach advocated by Graesser et al. (1997). First, we created a set of theoretical variables that we expected would predict readers' think-aloud comments. Each segment was coded for the occurrence of foregrounded features, as described earlier (i.e., a count of stylistic features at the phonetic, grammatical, and semantic levels). Next, the story segments were coded for situation model variables, following the method of Zwaan, Magliano, and Graesser (1995); of these, the new arguments variable proved the most robust predictor and is the only variable reported here. Also, since the literary story we used centers primarily on a single character (a young girl called Julia), we created a four-point scale for perspective, assessing the reader's degree of intimacy with this character. This scale ranged from no reference to the character, through external views of her behavior, to the invitation to share her perspective or her feelings through free indirect discourse (Miall \& Kuiken, in press).

In the upper portion of Table 3, we present partial correlations (controlling for segment 
length) between the frequency of each type of comment and the scores for each of these three story variables. It is noteworthy that foregrounding most powerfully predicts the frequency of associative comments, quotations, comments on style, and expressions of surprise. New arguments most powerfully predicts comments on style and imagery, suggesting the contribution of novel propositions to the vividness with which narrative events can be imagined. Perspective, on the other hand, is systematically related to explanations of character: the closer readers feel to Julia the more they seem impelled to formulate explanations for her behavior.

In a parallel study (Miall \& Kuiken, 1994a), we collected reading times per segment from 60 readers who read "The Trout" at their normal pace. Readers then reread the story and different groups provided one type of rating (e.g., strikingness, uncertainty, importance) for each story segment. In Table 3 we show correlations with reading times and two of the ratings, those for uncertainty (how uncertain readers were of the meaning of a given segment), and those for importance (how important to the meaning of the story the reader considered a given segment). Here, in contrast with Trabasso and Magliano's report (1996, p. 263) that the number of explanations predicts reading times, it is the production of associations, comments on style, and queries that predict longer reading times. The ratings for uncertainty suggest why this is so; the production of associations, comments on style, and queries also predict uncertainty (as do the number of quotations and expressions of surprise). Uncertainty, in other words, appears to signal an increased demand on processing resources that is characteristic of literary response. In this regard, it is important to note that uncertainty also correlates with the occurrence of foregrounding, as the intercorrelations in the lower half of Table 3 indicate.

The pattern of findings shown in this and the previous study, where we reanalysed responses to "The Demon Lover," point to the power of foregrounding as a major influence on literary readers. In addition, the second study suggests that, if the result of the encounter with foregrounding is defamiliarization, i.e., putting in question prior concepts or feelings, the resulting uncertainty creates a distinctive "control condition" for literary understanding. This is a rather different conception, however, from the control system envisaged by Zwaan $(1993,1996)$. While uncertainty may contribute to delaying formation of a situation model, as Zwaan has proposed, our perspective suggests that uncertainty, more significantly, heralds the transformations in understanding that occur during the reader's thematization of the literary text. As we have argued elsewhere (Miall \& Kuiken, 1994a, 1994b; Miall, 1995), it is during this process that feeling seems likely to play a critical role. As the vehicle of interpretation, guiding the "effort after meaning" (Bartlett, 1932, p. 44), feeling initiates a process in which existing schemata become recontextualized, leading to new insights for the reader. It is this process that we examine in the last section of this paper.

\section{Transformations of Personal Meanings}

The situation model components, and the inferential processes that support it, represent the basic components of comprehension that are probably obligatory and common for all readers. Foregrounding, in contrast, appears to provide a significant point of departure for individual differences in response to a literary text, particularly since it evokes feeling. Feeling appears to implicate the reader's self concept and to provide a route to specific issues relating to the self, as well as to experiences or memories that may provide a new interpretive context following the moment of defamiliarization. Thus, while all readers appear to be sensitive to foregrounding in literary texts, their construals of its meaning often differ widely, as studies such as the "Mariner" set of 
protocols demonstrate.

The modification or transformation of readers' concepts or feelings, the third component of literariness that we introduced earlier, is thus specific to the individual reader: it is in this respect, indeed, that literature seems to invoke what is individual in the individual. A second example from the same participant in the "Mariner" study shows how this process unfolds in a mode of response (shown in only some of the protocols in this study) that we call enactment, since it seems to involve actively living through a particular experience consequent on reading (for a more complete account, see Sikora, Kuiken, \& Miall, 1998). The verse selected by the reader comes late in the poem:

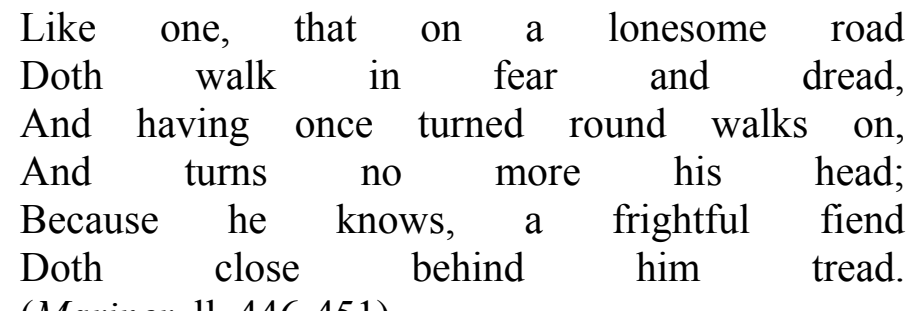

(Mariner, 11. 446-451)

I'm just going to share the emotion of being alone, in the dark, with this threat. Knowing that there's nothing you can do about it, keeping on walking and pretending it's not happening, just because there's no other way to cope with it, you can't run from it....I also sense there's no point in fighting this because, like it's a guilt thing, he's the one that's responsible for what's happened, he's the reason that this thing is following him, so there is no point in trying to get away from it because, it's your fate. It's just a bit of a reminder that everybody dies. Whatever's following him is going to get him. You don't know how long it's going to go and you don't know when it's going to get him, but you know that eventually that it will.

After exploring the feeling of being alone, the reader turns to the situation of the protagonist ("it's a guilt thing, he's the one that's responsible") and then makes an important generalization that seems to include herself. In this way the response unfolds in successive phases: initial awareness of a feeling with some personal relevance; the use of this feeling to locate a meaning for the poem; and the application of this notion to the position of the protagonist. Finally, in what is perhaps the most interesting part of the commentary, we see a convergence of the protagonist's situation with that of the reader: the "he" and "you" appear to become interchangeable. Although "this thing is following him," "it's your fate." The story understanding that emerges at this point appears to be "everybody dies." While this is certainly not a profound insight in itself, the way in which it is reached has made it personal to the reader, and enabled her to pursue a particular theme that seems to have concerned her throughout her reading of the poem (her first comment was "I seem to be picking on a bit of a theme of threatening").

In conclusion, the first two components of literariness, which include stylistic features or striking features due to narrative, and the reader's defamiliarizing response to them, are necessary but insufficient to identify literariness. The third component is constituted by the reader's attempts to articulate the phenomena within the text that are found striking and evocative of feeling. These attempts may be expressed in the type of 
comment that we earlier called thematizing. In our final example, we have illustrated a particular form of thematizing that we refer to as enactment: in such protocols taken as a whole, we find readers progressively transforming an affective theme across striking or evocative passages, becoming implicated in the existential concerns embodied in those passages, and experiencing a blurring of boundaries between themselves and the narrator.

We suggest that the conception of literariness can appropriately be grounded in this three-leveled analysis. The third level is the least well understood, and will require further carefully designed research studies (cf. Miall \& Kuiken, in press). But we believe that future empirical study is likely to show that these interacting components of literary response are not only distinctive, but also rest on a unique configuration of psychological and somatic responses. This, in the last analysis, is what gives literary response its enduring power in human cultural evolution.

\section{References}

Bartlett, F. C. (1932). Remembering: A study in experimental and social psychology. Cambridge: Cambridge University Press.

Bowen, E. (1981). The demon lover. In C. Brown (Ed.), The collected stories of Elizabeth Bowen (pp. 661-666). New York: Alfred Knopf.

Coleridge, S. T. (1924). The poems of Samuel Taylor Coleridge, ed. E. H. Coleridge. Oxford: Oxford University Press. (Original work published 1817)

Cook, G. (1994). Discourse and literature: The interplay of form and mind. Oxford: Oxford University Press.

Eagleton, T. (1983). Literary theory: An introduction. Oxford: Basil Blackwell.

Erlich, V. (1981). Russian formalism: History -- doctrine, 3rd ed. New Haven \& London: Yale University Press.

Fish, S. (1980). Is there a text in this class? The authority of interpretive communities. Cambridge, MA: Harvard University Press.

Fish, S. (1989). Doing what comes naturally: Change rhetoric, and the practice of theory in literary and legal studies. Durham, NC: Duke University Press.

Graesser, A. C. (1981). Prose comprehension beyond the word. New York: SpringerVerlag.

Graesser, A. C., Millis, K. K., and Zwaan, R. A. (1997). Discourse comprehension. Annual Review of Psychology, 48, 163-189.

Hobbs, J. R. (1990). Literature and Cognition. Stanford: Center for the Study of Language and Information. 
Hunt, R. A. \& Vipond, D. (1986). Evaluations in literary reading. Text, 6, 53-71.

Kintsch, W. (1988). The role of knowledge in discourse comprehension: A constructionintegration model. Psychological Review, 95, 163-182.

Kuiken, D., \& Miall, D. S. (1995). Procedures in think aloud studies: Contributions to the phenomenology of literary response. In G. Rusch, Ed., Empirical approaches to literature: Proceedings of the Fourth Biannual Conference of the International Society for the Empirical Study of Literature -- IGEL (pp. 50-60). Siegen: LUMIS-Publications.

Kuiken, D., Schopflocher, D., \& Wild, T. C. (1989). Numerically aided phenomenology: A demonstration. Journal of Mind and Behavior, 10, 373-392.

Miall, D. S. (1989). Beyond the schema given: Affective comprehension of literary narratives. Cognition and Emotion, 3, 55-78.

Miall, D. S. (1995). Anticipation and feeling in literary response: A neuropsychological perspective. Poetics, 23, 275-298.

Miall, D. S., \& Kuiken, D. (1994a). Foregrounding, defamiliarization, and affect: Response to literary stories. Poetics, 22, 389-407.

Miall, D. S., \& Kuiken, D. (1994b). Beyond text theory: Understanding literary response. Discourse Processes, 17, 337-352.

Miall, D. S., \& Kuiken, D. (1998). The form of reading: Empirical studies of literariness. Poetics, 25, 327-341.

Miall, D. S., \& Kuiken, D. (2001). Shifting perspectives: Readers' feelings and literary response. In W. Van Peer \& S. Chatman (Eds.), New Perspectives on Narrative Perspective (pp. 289-301). New York: SUNY Press.

Mukarovský, J. (1964). Standard language and poetic language. In P. L. Garvin (Ed.), A Prague School reader on esthetics, literary structure, and style (pp. 17-30). Washington, DC: Georgetown University Press. (Original work published 1932.)

O'Faoláin, S. (1980-82). The trout. In The collected stories of Seán O'Faoláin, Vol. I (pp. 383-386). London: Constable.

Sikora, S., Kuiken, D., \& Miall, D. S. (1998). Enactment versus interpretation: A phenomenological study of readers' responses to Coleridge's 'The Rime of the Ancient Mariner.' Paper presented at the Sixth Biannual Conference of the International Society for the Empirical Study of Literature -- IGEL. Utrecht, August 26-29. (Online at: http://www.arts.ualberta.ca/igel/IGEL1998/sikora.pdf)

Smith, B. H. (1988). Contingencies of Value: Alternative Perspectives for Critical Theory. Cambridge, MA: Harvard University Press.

Steen, G. (1994). Understanding metaphor in literature. London: Longman.

Trabasso, T., \& Magliano, J. P. (1996). Conscious understanding during comprehension. Discourse Processes, 21, 255-287. 
Van Dijk, T. (1979). Advice on theoretical poetics. Poetics, 8, 569-608.

Van Peer, W. (1986). Stylistics and psychology: Investigations of foregrounding. London: Croom Helm.

Zwaan, R. A. (1993). Aspects of literary comprehension. Amsterdam/Philadelphia: John Benjamins Publishing Company.

Zwaan, R. A. (1996). Toward a model of literary comprehension. In B. K. Britton \& A. C. Graesser (Eds.), Models of understanding text (pp. 241-255). Mahwah, NJ: Erlbaum.

Zwaan, R. A., Langston, M. C., \& Graesser, A. C. (1995). The construction of situation models in narrative comprehension: An event-indexing model. Psychological Science, 6, 292-297.

Zwaan, R. A., Magliano, J. P., \& Graesser, A. C. (1995). Dimensions of situation model construction in narrative comprehension. Journal of Experimental Psychology: Learning, Memory, and Cognition, 21, 386-397.

Zwaan, R. A., Radvansky, G. A. (1998). Situation models in language comprehension and memory. Psychological Bulletin, 123, 162-185.

\section{Author notes}

The first version of this paper was presented at the Sixth Biannual IGEL Conference, Utrecht, August 26-29, 1998. The authors would like to thank Rolf Zwaan for supplying the data from Zwaan et al. (1995) that forms part of the analysis reported in this paper. Also our particular thanks to Kees Van Rees, whose persistent questions led us to formulate this response to the problem of what constitutes literariness, and to the three reviewers of this paper whose trenchant comments on an earlier draft helped us to clarify our arguments.

The research reported here was supported in part by programme grant \#53-10128 from the Social Sciences and Humanities Research Council of Canada. Correspondence and requests for reprints should be sent to David S. Miall, Department of English, University of Alberta, Edmonton, Alberta, Canada, T6G 2E5; David.Miall@Ualberta.Ca. 